\title{
Fatigue Durability Analysis of Collecting Rapping System in Electrostatic Precipitators under Impact Loading
}

\author{
Ali Akbar Lotfi Neyestanak, Saeed Adib Nazari, Ali Imam, and Cyrus Aghanajafi \\ Department of Mechanical and Aerospace Engineering, Science and Research Branch, Islamic Azad University, \\ Tehran 14778 93855, Iran \\ Correspondence should be addressed to Ali Akbar Lotfi Neyestanak; aaklotfi@yahoo.com
}

Received 29 July 2013; Revised 24 November 2013; Accepted 2 December 2013; Published 12 January 2014

Academic Editor: Martha Guerrero

Copyright (C) 2014 Ali Akbar Lotfi Neyestanak et al. This is an open access article distributed under the Creative Commons Attribution License, which permits unrestricted use, distribution, and reproduction in any medium, provided the original work is properly cited.

\begin{abstract}
Due to the importance of collecting rapping system in electrostatic precipitators (ESP) and controlling the relevant damage under impact loading, fatigue durability of this system is analyzed in the present study based on the numerical and experimental results considering fatigue damage growth and vibration acceleration in the collecting system because of the successive impact of rapping hammers. By microscopic examination of the fracture surface of rapping hammer, beach marks obviously show typical fatigue failure in the rapping hammer arm. In addition, the microscopic examination of the cross section of the collecting plates indicates the corrosion voids which cause crack and eventually fatigue failure. The finite element method is applied to determine both the stress and concentration positions of dynamic stress on the rapping system under impact loading. The paper results can be utilized in system optimization and new material selection for the system by evaluating rapping system durability.
\end{abstract}

\section{Introduction}

Dust particles of combustion gases produced in various industries such as cement industry, copper melting, and iron melting play a significant role in environmental pollution $[1,2]$. Therefore, to prevent emitting the dust into the environment, electrostatic precipitators (Figure 1) have been utilized in which a strong electrostatic field is applied to migrate dust particles and produced gas through the plates and electrodes. Then the gas and particles become ionized in the field (corona formation) and charged dust particles immigrate toward the collecting plates [3-5]. Finally by depositing a portion of dust particles on the discharge electrodes and according to the viscosity and the dust type of different industries a rapping system will be needed to make a vibration with proper acceleration and amplitude on the collecting plates (Figure 2) [6].

According to the investigations, the minimum acceleration to separate a dust cake of deposited dust particles on the collecting plates from these plates is $100 \mathrm{~g}\left(980 \mathrm{~m} / \mathrm{s}^{2}\right)(\mathrm{g}$ is gravitational acceleration). The minimum and maximum accelerations caused by rapping on the collecting plates are illustrated in Figure 2. So, with the parameters like thickness, frame dimension, and material of collecting plates, the sufficient energy obtained by rapping should be provided in order to make such an acceleration throughout the frame. Then the produced acceleration in the collecting plates is given in (1) by considering fundamental frequency and displacement made in the collecting plates resulting from rapping hammer $[6,7]$. Consider

$$
\text { acceleration }=4 \pi^{2} f^{2} d,
$$

where $d$ is displacement caused by rapping on the collecting plates (meter) and $f$ is fundamental frequency $(\mathrm{Hz})$. Fundamental frequency is given in relation (2) considering the dimension, weight, and material of the collecting plates. Consider

$$
f=\frac{K}{2} \times\left(\frac{D}{w L^{4}}\right)^{1 / 2},
$$

where $K$ is constant, $L$ is the width of the collecting plate $(\mathrm{m}), w$ is weight per unit area, and $D$ is the stiffness of the collecting plate which is given in relation (3). Consider

$$
D=\frac{E t^{3}}{12\left(1-v^{2}\right)},
$$




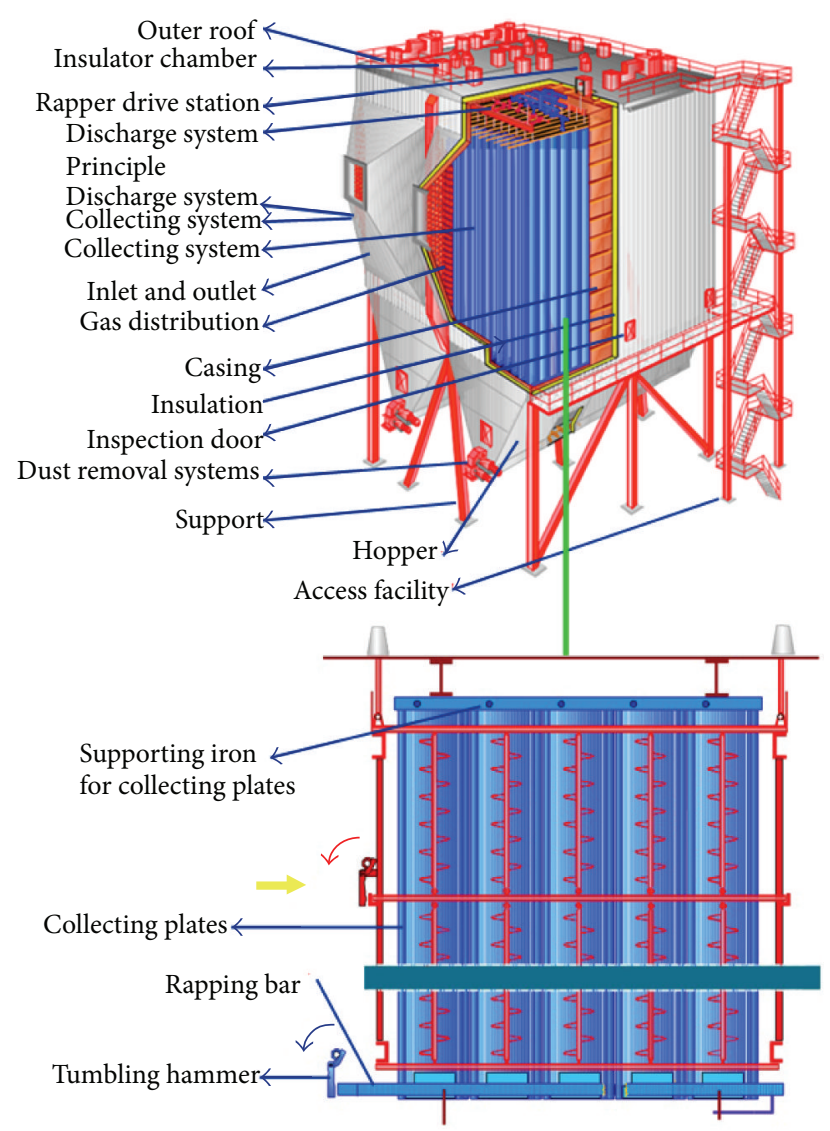

FIGURE 1: Electrostatic precipitator, collecting plates, and rapping system.

where $t$ is collecting plate thickness in meter, $v$ is Poisson ratio, and $E$ is elasticity modulus of collecting plates.

Furthermore, according to the essential acceleration to separate dust cake from collecting plates, in a rapping system with hammer, by considering the weight and hammer arm length, a part of the generated energy from the rapping of the hammer causes vibration in collecting plates or discharged electrodes and leads to separation of deposited dust particles on the plates and electrodes. In the present hammers, according to the limitation in hammer length increase due to the increase in work space in addition to the limitation of hammer weight increase, both maximum vibration acceleration on the collecting plates and the concentration of the stresses caused by rapping are reduced with a proper design of the hammer shape [6-8].

The previous researches were mainly focused on the vibration created in the rapping system by rapping of the hammer [8-11]. But, fatigue failure durability of rapping hammer and dynamic stresses of rapping on it besides the effect of vibration acceleration on the collecting plates are studied in the present survey which has already been ignored by considering the effect of the wave propagation resulting from rapping throughout the plates length on the plates life. So, in order to investigate the fatigue failure of rapping hammer and collecting plates, firstly the effect of dynamic

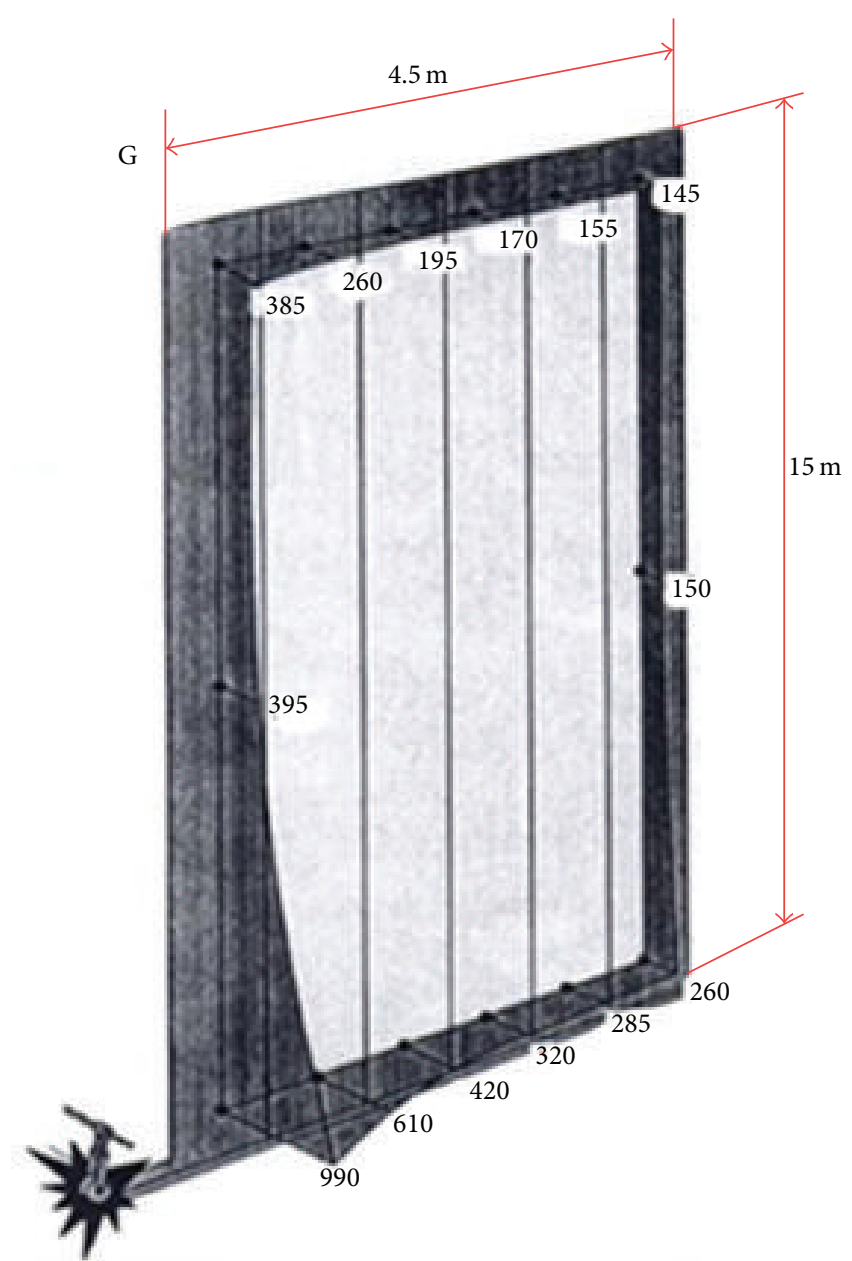

FIGURE 2: Rapping system of collecting plates and the amount of acceleration in different points of the collecting plates.

stresses of rapping on the system (hammer and collecting plates) and then the acceleration caused by rapping on the collecting plates of the system have been analyzed. The aim of this paper is to achieve the sufficient vibration acceleration on the collecting plates considering wave propagation in the plate length due to rapping and gaining the lifetime of these plates by applying finite element method in addition to the experimental investigations on constructed pilot's tester.

Dynamic motion of hammer is also modeled because the kinetic energy of the hammer rotational motion is devoted to make vibration acceleration in a proper area with high frequency in collecting plates during impacting on the system.

\section{Fatigue Failure in Rapping System}

2.1. First Case: Fatigue Failure in Rapping Hammer. A portion of rapping energy is devoted on elastic deformation and if this amount of energy is discussed in the stress analysis done on the rapping hammer it can create dynamic stresses on the hammer body; in the case of rapping hammer the maximum amount of dynamic stress is concentrated on the 


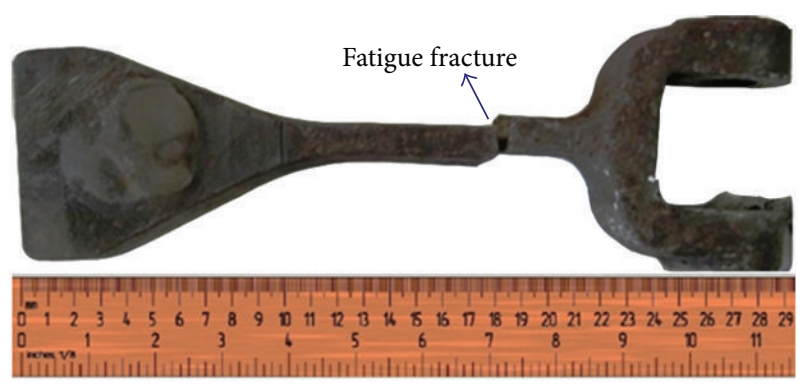

FIGURE 3: Hammer fatigue fracture location.

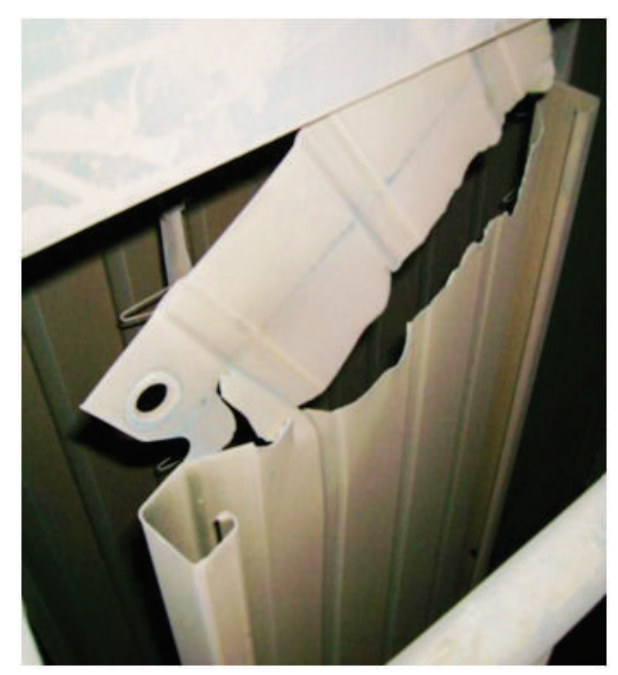

FIgURE 4: The location of collecting plate ruptures.

hammer arm. Therefore, in the experimental investigations rapping hammer will be fractured (by fatigue) in a600000 impact cycle because of dynamic loads of rapping. The fracture location of rapping hammer is shown in Figure 3. The aim of the present study in such a case is to analyze the fracture in order to determine and describe the main factors in the fracture of hammer and to use appropriate analysis techniques which can be suitable to design optimum production method for these hammers.

2.2. Second Case: Ruptures Investigation of Collecting Plates. A portion of energy is also devoted to vibration in the plate and eventually leads to elastic deformation. By considering the wave propagation through the plates created by the impact, the vibration acceleration of the collecting plates causes frequent deformations on the plate. If this amount is considered in the stress analysis of the collecting plates, it can produce dynamic stresses on the plates. The location of these dynamic stresses concentration in the plates is close to the locations which are restricted. So, according to Figure 4 durability rupture of collecting plates exactly occurrs in such a place where there is the maximum stress. In this case, the aim of the paper is to analyze rupture fracture in order to determine and describe the main parameters of the collecting

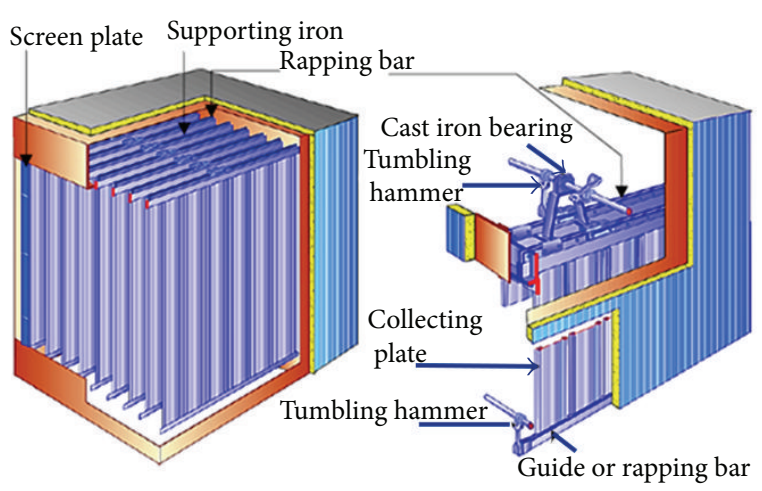

Figure 5: Rapping system, collecting plates (FLS Group, Inc.) [9].

TABLE 1: Profile parameters of collecting rapping system.

\begin{tabular}{lcc}
\hline Profile & Hammer & Collecting plate \\
\hline Heights $H(\mathrm{~m})$ & 0.29 & 12.5 \\
Mass $m(\mathrm{~kg})$ & 6.9 & 98 \\
Thickness $t(\mathrm{~mm})$ & 40 & 1.5 \\
Length $L(\mathrm{~m})$ & - & 0.5 \\
\hline
\end{tabular}

plates rupture, in addition to affording achieving a proper vibration in the plates without any damage and fracture.

\section{Characteristics and Properties of the Rapping System Materials}

Collecting plates and rapping hammer are the principle elements of EPS. The height of the collecting plates varies between 1 and 15 meters according to the desired collecting efficiency and input gas volume; in addition, the weight of the rapping hammer changes from 4 to $8 \mathrm{~kg}$ considering the plate height and necessary vibration acceleration. Rapping system including the collecting plates besides rapping hammer and all its elements is illustrated in Figure 5. The geometrical characteristics of the collecting plate and rapping hammer which are studied in this work are given in Table 1. Both XRF (X-ray fluorescence spectrometry) and optical emission spectrometry methods (quantometer) were applied to do precise chemical analysis of hammer and collecting plates. The results are shown in Table 2(a).

On the other hand, their mechanical properties were obtained by means of Gotech universal tensile testing machine with the capacity of 30 tons; in addition, preparing the sample with a flat cross section and a gage length of $80 \mathrm{~mm}$ was done according to standard EN10002-1 (DIN EN 10130). Furthermore, Impact value Charpy v Notch test was done for the hammer according to standard En 10045. The results are given in Table 2(b) gives. But, in the condition of more intensive corrosive environment more corrosionresistant steel like SS316 will be used. The manufacturing process of these plates is rolling. The collecting plates inside the electrofilter shell are suspended and they are restricted at the top of the plates in a steel frame. Rapping hammer material done by chemical analysis and tensile mechanical 
TABLE 2: Characteristics of examined colleting plates and rapping hammer.

(a) Chemical specifications

\begin{tabular}{|c|c|c|c|c|c|c|c|c|}
\hline \multirow{2}{*}{ Element } & \multicolumn{8}{|c|}{ Composition (\%) } \\
\hline & $\mathrm{C}$ & $\mathrm{Si}$ & Mn & $\mathrm{P}$ & S & $\mathrm{Cr}$ & $\mathrm{Ni}$ & Mo \\
\hline Collecting & 0.131 & 0.202 & 0.889 & 0.0167 & 0.005 & 0.0081 & 0.0344 & 0.0050 \\
\hline Hammer & 0.332 & 0.28 & 0.561 & 0.007 & 0.022 & 0.082 & 0.081 & 0.01 \\
\hline
\end{tabular}

(b) Mechanical properties

\begin{tabular}{lccccc}
\hline & Yield strength (Mpa) & Tensile strength (Mpa) & Elongation (\%) & $\begin{array}{c}\text { Impact value Charpy v } \\
\text { Notch (long.) }\end{array}$ & Modulus of elasticity (Gpa) \\
\hline Collecting & 253 & 324 & 36 & - & 200 \\
Hammer & 314 & 562 & 16 & 41 & 210 \\
\hline
\end{tabular}

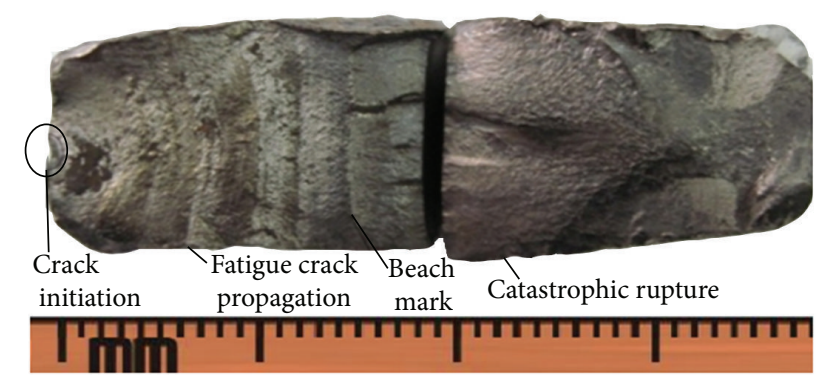

FIGURE 6: Fatigue fracture cross section of rapping hammer arm.

test is given in Table 2. The hammer material is steel Ck35 and formed and produced by forging operation.

\section{Study of Fracture Surface}

4.1. Visual Investigation into Fatigue Damage of Rapping Hammer. Cross section of the fracture is seen in two sections in Figure 6. The left one with a flat surface and half part of fracture surface shows fatigue damage. On this section, fatigue fracture surface without any plastic deformation has a flat surface and the fracture surface is approximately perpendicular to the principle stress-strain axis on the hammer. Fatigue fracture initiates from the pints of stress concentration on the rapping hammer arm and continues to reduce cross section of hammer arm up to the point that cross section is so small that the relevant stress of this cross section exceeds the allowable stress. Then, according to Figure 6 the hammer undergoes sudden fatigue rupture. On the right section of Figure 6, the reason of final fracture is the fact that the remaining cross section cannot bear the applied load.

4.2. Steps of Fatigue Fracture in Rapping Hammer. Fatigue crack initiates in the first step and as seen in Figure 6, it (this crack can be created because of the hammer contact with the rapping shaft at the surface besides the remaining stresses and scratches caused by forging operation at the surface) initiates from the points of stress concentration on the surface of rapping hammer arm and extends toward the center of hammer arm. After reaching the center, because of the cracks

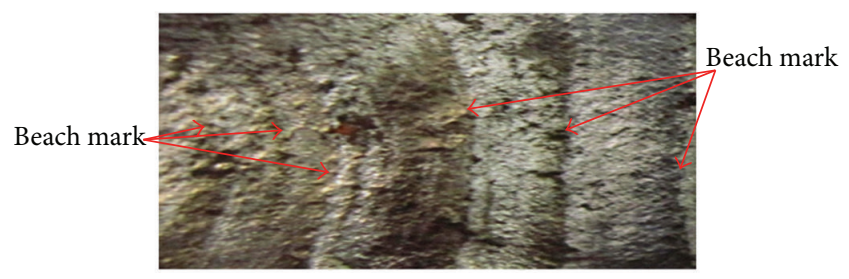

FIgURE 7: On fatigue fracture surface of hammer.

caused by hammer trim and after forging operation, fracture route will differ by 90 degrees and eventually because of the concentration of dynamic stresses, the hammer undergoes the catastrophic uterine rupture [12-17].

4.3. Optical Microscopy Investigation on Fatigue Fracture of Rapping Hammer. The presence of beach marks, clearly shown in Figure 7, is one of the main characteristics of fatigue. According to Figure 7, with microscopic investigation into the fracture surface of hammer, a group of concentric circles are seen at the cross section of fatigue fracture by the use of an optical microscope with 100x magnification in which their curvature is toward the initial point of fatigue crack. These circular lines called beach mark or arrest mark obviously show fatigue fracture of hammer at the plate perpendicular to the hammer axis. Beach marks show high cycle fatigue in the rapping hammer before reaching the middle axis of the hammer. Furthermore, hammer vibration in consecutive impacts which cause consecutive dynamic stresses is probably formed by propagation of initial crack which resulted from the production process and leads to failure of rapping hammer. A main area of the fracture surface presents high stress failure facies. A more detailed analysis of the fractured surface concludes that the surface that failed by fatigue is clearly less than the one that failed by overload; this measuring capacity allows the investigator to consider that failure occurred by fatigue but in the presence of high stress levels at the initiation zone. The fatigue area was relatively small, $20 \%$ of the whole fracture area. Rupture of Collecting Plates. Figure 8 shows the image of 


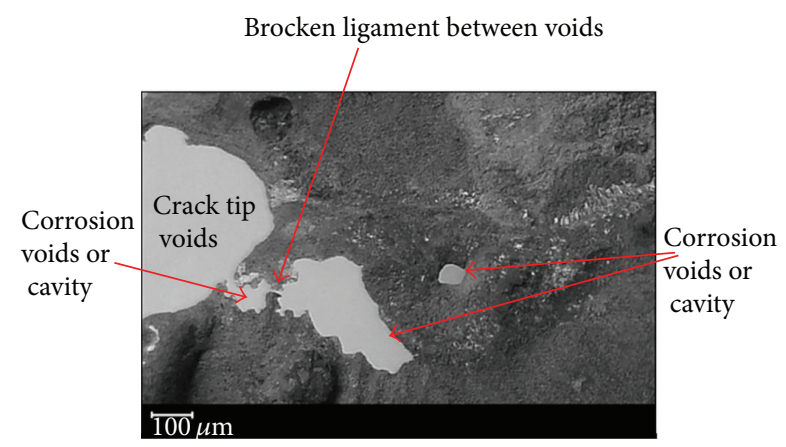

FIgURE 8: Crack tip voids formation and coalescence in a ductile fracture process of collecting plate.

rupture surface in the collecting plate. As seen in this figure, according to the mechanical properties of the collecting plates, they are characterized by flexible and not brittle material behavior. So, considering the effects produced by corrosion or other elements of the metallic matrix (as illustrated in Figure 8), final collapse is followed by cavities or voids growth, coalescence, and fracture of collecting plates.

Also SEM image of rupture surface in the collecting plate with high resolution is indicated in Figure 9. This image illustrates the primary defects of corrosion; in addition, fracture surface clearly shows the fatigue rupture perpendicular to the axis of collecting plate and in direction of impact. Moreover, rims and striation marks at a noticeably flat surface imply fatigue rupture and very small distance between rims indicates small distance between striation marks and finally shows high cycle fatigue rupture in the collecting plates.

It is noteworthy that collecting plates bear high dynamic stresses because of the vibration caused by consecutive rapping on these plates and the weight of the plates which leads to static stresses.

\section{Dynamic Stresses Analysis of Rapping System}

In this section, dynamic stress on the collecting plate and rapping system body, produced by frequent impacts on the rapping system to remove deposited dust cake of the collecting plates, is analyzed with numerical method, utilizing finite element technique and Abaqus software (version 6.101) [18]. The results of the finite element analysis are verified by applying experimental results, vibration analysis of the system, and rupture location of the piece.

5.1. The Dynamics of Rotational Motion of Hammer. Besides applying experimental results, dynamic motion of hammer before rapping, angular velocity, and kinetic energy of the hammer just before the impact are calculated to verify the finite element results. Finally, return angle after rapping as well as angular velocity and kinetic energy of the hammer after rapping is obtained with practical experiments. This measurement is done by calculating the amount of energy which includes the dissipated sound energy of all the energies causing elastic deformation and vibration in the rapping

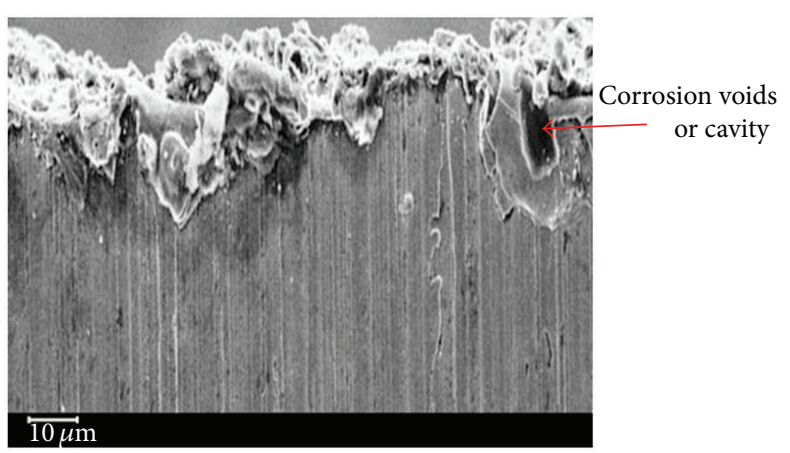

FIGURE 9: SEM image of a cross-section rupture of the collecting plate (corrosion pits near fracture surface).

system. Eventually, by doing practical experiments, it is possible to determine the energy which causes vibration in the collecting plates and motion in the system. The accuracy of numerical results is proved by comparing the results of experimental and numerical analysis. Therefore, considering the dynamic motion of the hammer, it is possible to use relations (4) to (9) to validate the results obtained by the software and experimental results. Consider

$$
\omega=\sqrt{\frac{2 m g \bar{r}}{I_{O}}},
$$

where $\omega$ is the angular velocity of a hammer, $m$ is the hammer Mass, $\bar{r}$ is the distance centre of mass from the axis of hammer rotation, and $I_{O}$ is the moment of inertia around an axis of hammer rotation. Consider

$$
\begin{gathered}
E^{P}=m g h, \\
E^{K}=0.5 I \omega^{2},
\end{gathered}
$$

where $I$ is the moment of inertia, $h$ is the hammer height, $E^{P}$ is the potential energy of the hammer before rapping, and $E^{K}$ kinetic energy of the hammer before rapping.

Furthermore, according to energy conservation law, after rapping, kinetic energy of the hammer at the moment of rapping converts to the energies given in relation (6) so it is possible to have strain energy produced in the hammer and system. Consider

$$
E^{T}=E_{1}^{E}+E_{2}^{E}+E^{r}+E^{b}+E^{a},
$$

where $E^{T}$ is the total energy after hammer rapping and includes

$E_{1}^{E}$ : strain energy produced in the system, $E_{2}^{E}$ : strain energy produced in rapping hammer, $E^{r}$ : return kinetic energy in the hammer, $E^{b}$ : kinetic energy in the plates, and $E^{a}$ : the energy dissipated as sound.

The strain energy produced in the system is

$$
E_{1}^{\varepsilon}=0.5\left(\sigma_{1} \varepsilon_{1}+\sigma_{2} \varepsilon_{2}+\sigma_{3} \varepsilon_{3}\right)
$$

and for the strain energy in the rapping hammer there is

$$
E_{2}^{\varepsilon}=0.5\left(\sigma_{1} \varepsilon_{1}+\sigma_{2} \varepsilon_{2}+\sigma_{3} \varepsilon_{3}\right) .
$$




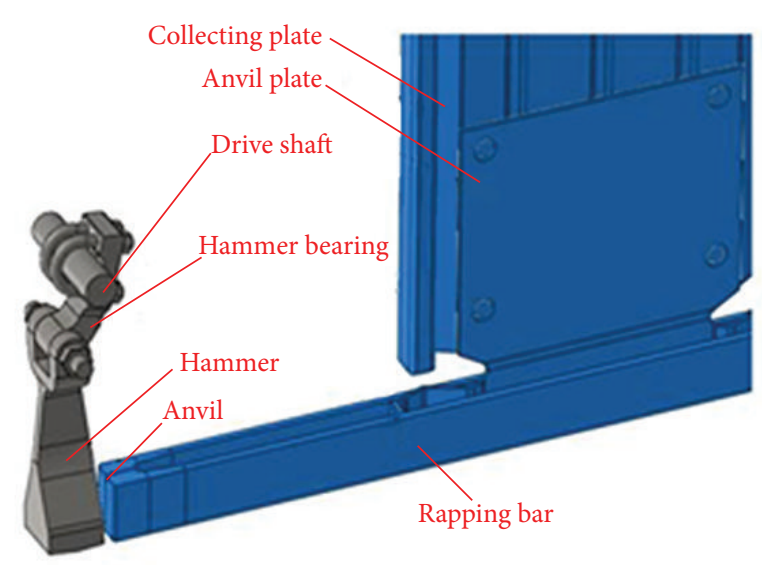

FIGURE 10: Numerical modeling relevant to all parts of the collecting plates and rapping system of the electrostatic filter (tumbling hammer, anvil plate rapping bar, and collecting plate).

According to relation (9), the equation of minimum potential energy in the case of dynamic matters also validates the results obtained by numerical analysis. Consider

$$
\begin{aligned}
\int_{V}(\delta \varepsilon)^{T} \sigma d V= & \int_{V}(\delta u)^{T} b d V+\int_{S}(\delta u)^{T} S d S+\sum_{p=1}^{N}(\delta u)^{T} f_{p} \\
& -\int_{V}(\delta u)^{T} \rho \ddot{u} d V-\int_{V}(\delta u)^{T} \mu \dot{u} d V .
\end{aligned}
$$

5.2. Modeling the Rapping System of Electrostatic Precipitator. In this section, to analyze the dynamic stresses on the collecting plates and the body of the rapping hammer in order to remove deposited dust cake of the collecting plates by frequent impacts on the rapping system, 3D modeling of rapping hammer and dust collecting plates is done and then these 3D models are discussed by finite element method and Abaqus. Element C3D8R is applied to mesh the rapping system, shaft, anvil, and collecting plates. This element is used when there is no geometrical complication and more precise analysis is required. Conventional 3D elements have freedom degrees of rotation and displacement. The chosen elements of collecting plates are the conventional shell type or S4R. This element has both thick and thin shell together. Modeling of the system is shown in Figure 10.

5.3. Stress Analysis of the Rapping Hammer. Rapping and relevant dynamic stresses analysis is done after modeling the hammer. Rapping shaft is completely restricted in this analysis and the hammer has a rotational motion around the shaft axis because of its weight. According to this motion and considering the hammer and anvil surfaces as the contact surfaces, after reaching the hammer to the anvil they will contact because of the hammer weight and rotational motion around shaft axis. Therefore, because of rapping, a part of the energy of rotational motion of the hammer is converted to the strain energy in hammer and anvil so it creates stress in

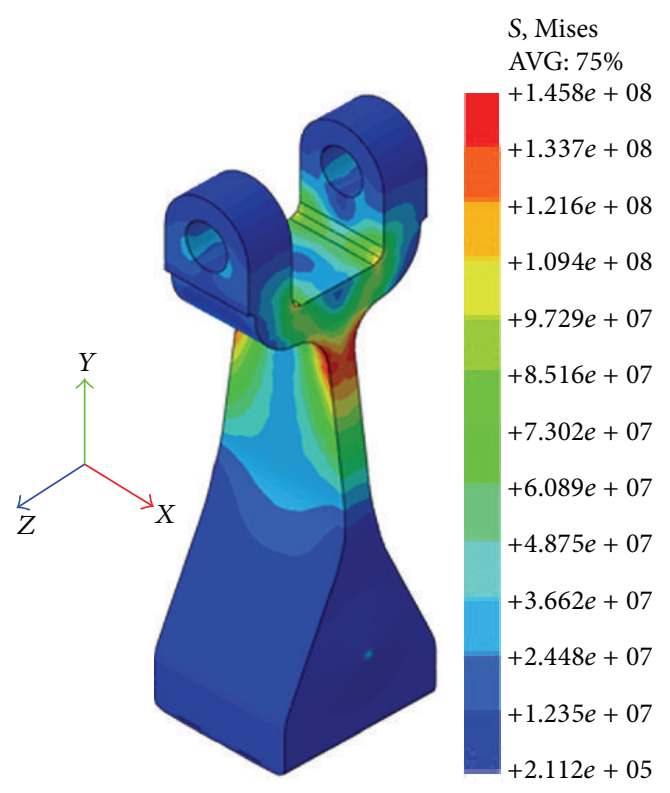

FIGURE 11: Maximum dynamic von Mises stresses in the hammers.

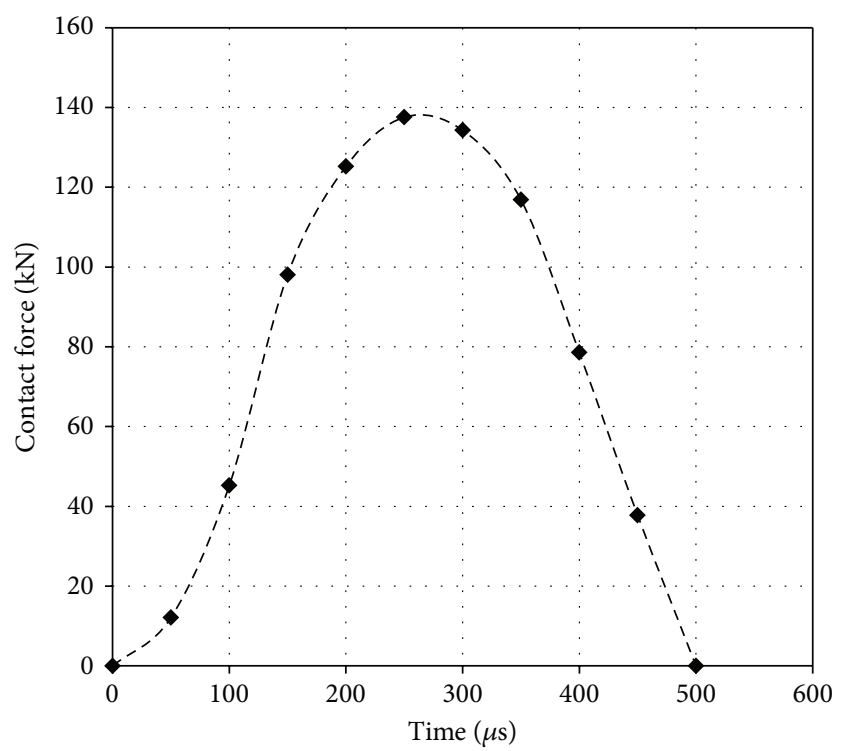

FIGURE 12: Impact force of the swing hammer on the bar supporting the electrodes.

them. According to the results of the analysis in Figure 11, it is possible to observe the maximum dynamic von Mises stress along $y$-axis and both sides of neutral axis in 3D model of the hammer.

So, as seen in Figure 11, the maximum von Mises stress on the arm of hammer, which is so effective in reducing the hammer life, is $145 \mathrm{Mpa}$. In addition, the maximum stress is exactly close to the fracture location so optimizing the rapping hammer profile is suggested to increase hammer life.

Figure 12 shows the dynamic force created after rapping along $y$-axis on the rapping bar. According to this diagram, the maximum amount of this force is $135 \mathrm{KN}$. So, by applying 

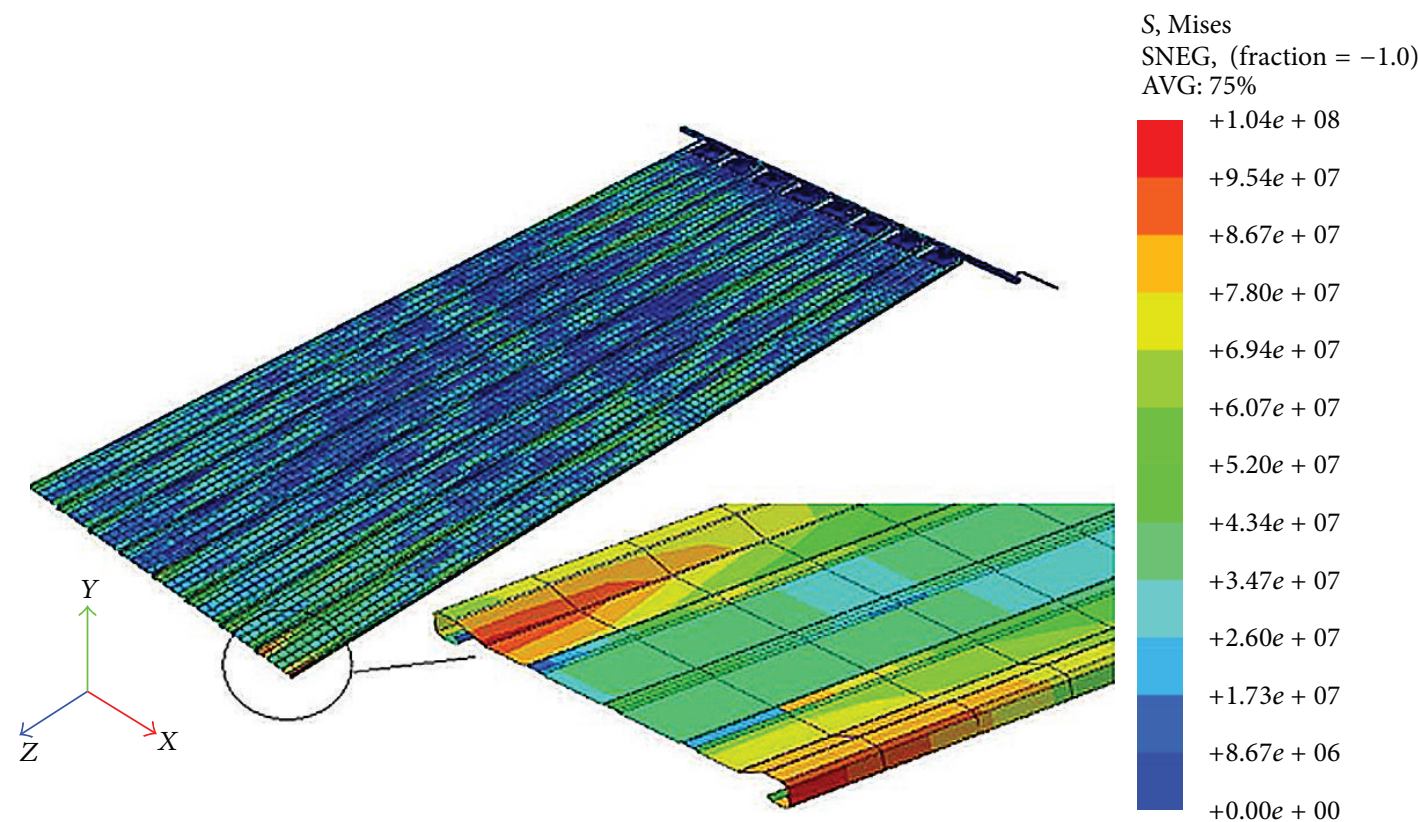

Figure 13: Maximum dynamic von Mises stresses in the collecting plate.

dynamic force caused by rapping, vibration with high acceleration is expectable on the plates [11, 19]; in addition, dynamic stresses resulting from plates vibration are evaluated [20].

5.4. Stress Analysis of Collecting Plate. The results of dynamic stresses because of rapper impact on the collecting plates are illustrated in Figure 13. According to the analysis, it is possible to observe maximum dynamic stress in 3D model of the system. Figure 13 shows the stress distribution in a group of collecting plates with mentioned material properties in Table 2. According to this figure, the noticeable part of stresses is below 100 megapascal. Also, it is indicated that the maximum stress distribution is just after impact and it is obviously seen that this maximum amount of von Mises stress on the plate is at the top of the plate and near the plate constraints; in addition, as seen in Figure 4 plates rupture also occurrs in this location and in a place where there are the maximum dynamic stresses. Considering the maximum applied stress on the plates in addition to mechanical properties of them, given in Table 2, it is clearly seen that dynamic stresses are not the only reason for rupture but primary defects and holes caused by corrosion or rolling process of the plates and their fatigue during the frequent loading as well as.

Finally, since separating particles from the collecting plates acceleration is one of the main parameters in removing dust particles, it is observed by drawing the diagrams of acceleration variation with time that collecting plates system has an oscillation with short amplitude and high frequency. Acceleration variation of the plates with time because of the rapping hammer impact on these plates is shown in Figure 14 and the relevant results are given. According to the experiments, in order to prevent throwing the particles toward forward and creating dust particles between the collecting

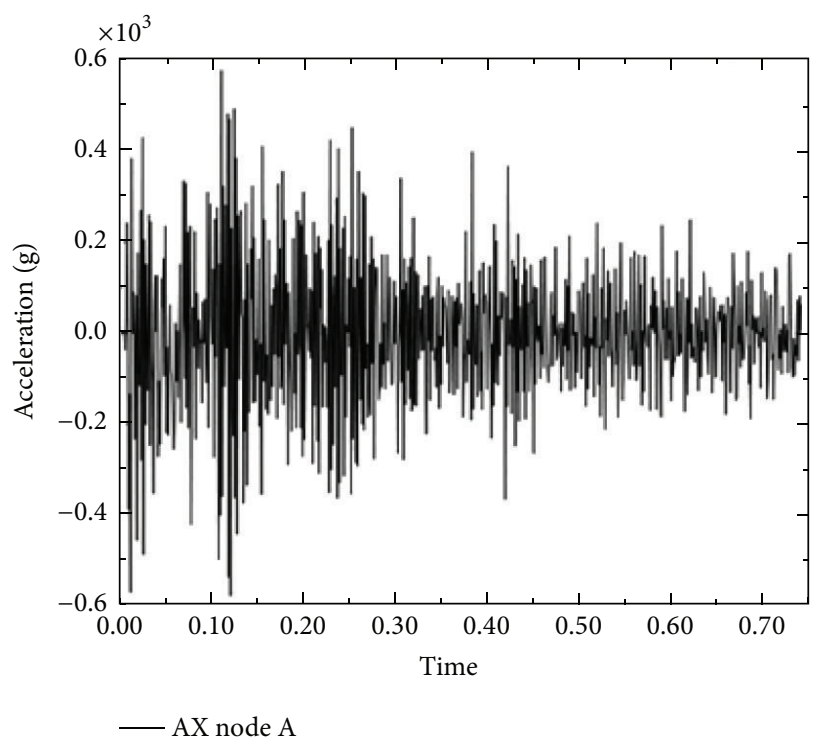

FIGURE 14: Amplitude of vibration acceleration of collecting plate at the measuring point A obtained from simulations.

plates, the acceleration perpendicular to the plates should be of small amount; on the other hand, the acceleration parallel to the plates should be of large amount to facilitate particle drops downwards. As seen in Figure 14, the acceleration parallel to the plates has the maximum amount, around $600 \mathrm{~g}$, at point A (this point is schematically indicated in Figure 16). This diagram is also used to evaluate the results accuracy of analysis done by finite element method and compared with experimental results of accelerometer in a similar point (point A). 


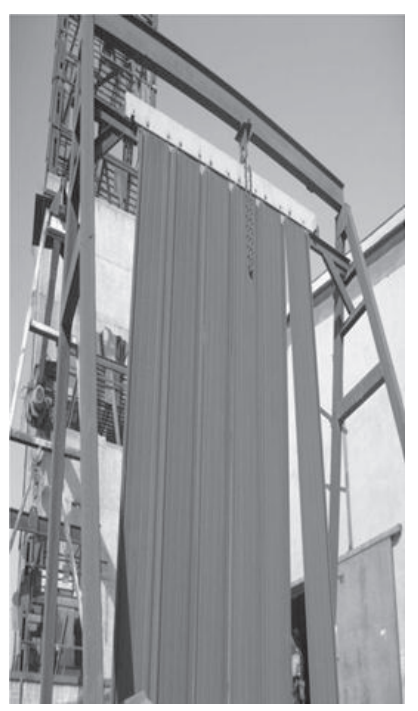

FIGURE 15: Test unit for measuring accelerations of collecting plate (JDEVS).

\section{Experimental Study}

6.1. Description of Applied Equipment in the Test. The acceleration is caused by rapping on a screen with six collecting plates with real dimensions in which the length and width of each plate are $12500 \mathrm{~mm}$ and $500 \mathrm{~mm}$, respectively, and is measured in a pilot's tester constructed for this purpose in JDEVS (Figure 15 illustrates this pilot's tester). So, in order to measure the acceleration on these plates, accelerometer B\&K type-2635 with a weight of $2 / 4 \mathrm{~kg}$ which calibrated with the accelerometer B\&K type-4294 was utilized; besides, it was connected to a charge amplifier B\&K type-2635. In the previous studies a similar pilot's tester was used.

6.2. Measurement of the Acceleration Caused by Rapping on the Collecting Plates. At first, as shown in Figure 16, the accelerometers are connected to the collecting plates at $2 \mathrm{~m}$ distance vertically and horizontally as the main accelerometer axis is perpendicular to the surface. (Figure 16 schematically shows the collecting plates and their distances from the accelerometers installed on the screens.) By releasing the hammer at degree 180 and impacting to anvil the energy resulting from hammers motion, which is about $38 \mathrm{~J}$ and includes strain energy produced in the hammer and collecting plates, kinetic energy converts to returning motion in hammer, collecting plate's motion, and sound energy. Transferred energy from hammer to collecting plates causes vibrations with very small amplitude and high frequency besides, high acceleration in the collecting plates. Figure 17 shows the results of the accelerometers. As seen in this $3 \mathrm{D}$ diagram, the maximum acceleration is obtained as it gets closer to the rapping location (the maximum measured acceleration on the second plate of the collecting screen is $850 \mathrm{~g}$ ) and the acceleration is reduced as it gets further from this location toward the top of the plate or the end of the collecting plate screen. According to the diagram, the

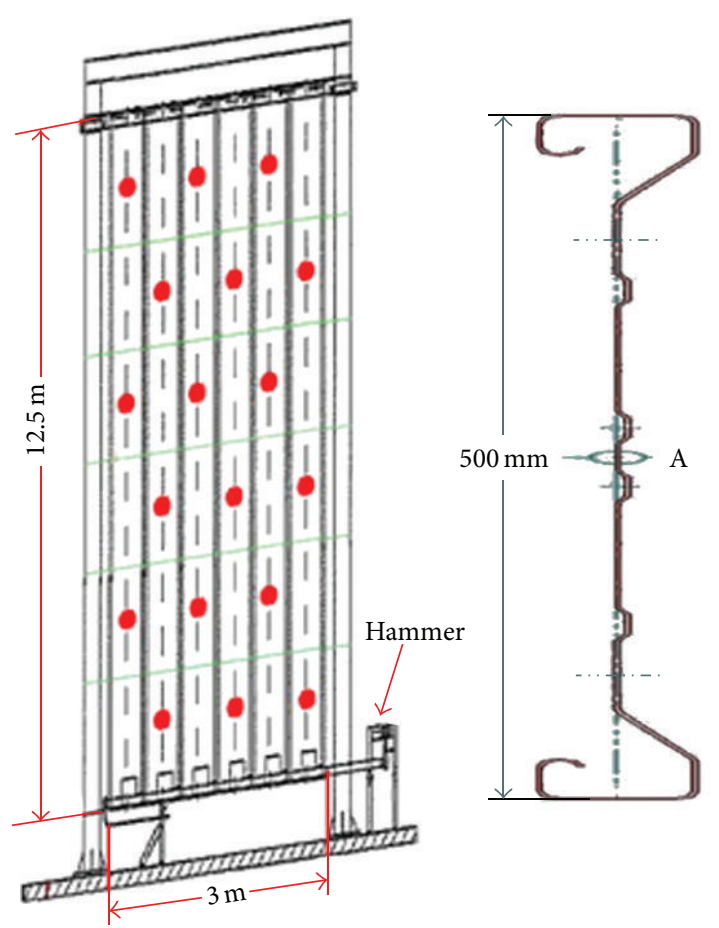

FIGURE 16: Schematic image for the frame consists of six collecting plate used for acceleration measurements (red points show the locations of the accelerometers).

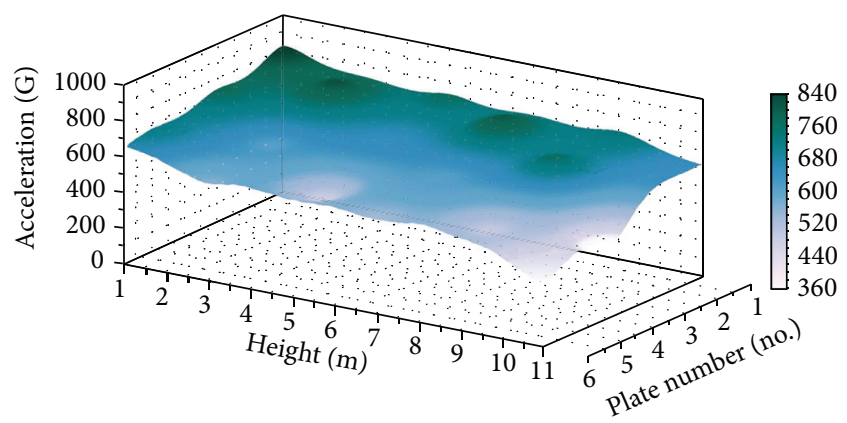

FIGURE 17: Result of accelerometer measurements at the points in which the accelerometers installed on the collecting plates (with six plates).

minimum acceleration equals $350 \mathrm{~g}$ at the height of $11000 \mathrm{~mm}$ and at the last plate of the collecting screen by noting the dimension of the collecting plates and their numbers in the screen. This amount can be proper considering the required energy to separate dust cake from the collecting plates.

\section{Conclusion}

The following results are obtained according to the investigations of the rapping system of the collecting plates besides the numerical and experimental analysis of the rapping hammer and collecting plates.

First Case: Rapping Hammer. By studying the remaining effects at the fracture surface of rapping hammer, it can 
be mentioned that damage initiates in rapping hammer because of primary superficial defects caused by the hammer impact on the rapping shaft at the surface or because the scratches resulting from forging operation at the surface. Some observations such as beach mark indicate that the hammer bears high cycle fatigue after crack expansion. Therefore, fatigue crack extends from concentration location of dynamic stresses at the surface of rapping hammer arm towards the center of hammer arm. After reaching the arm center, because of the cracks caused by hammer hot trim followed by forging operation, fracture direction changes $90^{\circ}$ and eventually rapping hammer bears catastrophic uterine rupture because of the concentration of dynamic stresses there.

With changes in geometrical shape and optimizing the hammer design, it is possible to reduce the stress concentration on the hammer arm which leads to reducing the energy of elastic deformation in the hammer. This stress reduction significantly helps to increase rapping hammer life. Furthermore, to manufacture a hammer without any critical defects, it is necessary to observe design, control, and optimization of forging operation such as proper hot trim, superficial defects reduction, and removing the friction between hammer and rapping shaft.

Second Case: Studying the Collecting Plates Ruptures. Vibration and wave propagation in the collecting plate because of rapping produce frequent deformations on the surface and can cause dynamic stresses on the plates. Dynamic stress concentration is at the top of the plate and close to the locations where these plates are restricted. So, since fatigue rupture of the collecting plates occurs at the location where there is maximum stress, it can be validated on the analysis in FEM with noting the location of stress concentration. But, considering that both maximum dynamic stresses and mechanical properties of the plate materials can cause rupture, it confirms that the main factors of rupture are the primary defects and holes produced by corrosion or the defects created by rolling process and plates fatigue during frequent loading. Moreover, rupture surface of the plate obviously shows fatigue rupture perpendicular to the collecting plates axis and in the direction of rapping. The rim sand striation marks in a flat surface indicate soft fatigue rupture; in addition, very short distance of striation marks shows high cycle fatigue of the collecting plates.

\section{Conflict of Interests}

The authors declare that there is no conflict of interests regarding the publication of this paper.

\section{Acknowledgments}

The authors gratefully acknowledge financial and technical support by the Iranian Academic Center for Education, Culture and Research, Branch of Science and Technology University (JDEVS).

\section{References}

[1] D. A. Lloyd, Electrostatic Precipitator Handbook, A. Hilger, Bristol, UK, 1988.

[2] J. Harry, Industrial Electrostatic Precipitation, International Society of Electrostatic Precipitation (ISESP), Addison-Wesley, 1963.

[3] A. Mizuno, "Electrostatic precipitation," IEEE Transactions on Dielectrics and Electrical Insulation, vol. 7, no. 5, pp. 615-624, 2000.

[4] K. J. McLean, "Electrostatic precipitators," IEE Proceedings A, vol. 135, no. 6, pp. 347-361, 1988.

[5] J. Katz, The Art of Electrostatic Precipitation, Precipitator Technology, Munhall, Pa, USA, 1979.

[6] K. R. Parker, Ed., Applied Electrostatic Precipitation, Blackie Academic and Professional, London, UK, 1997.

[7] K. Parker, Electrical Operation of Electrostatic Precipitators, 2007.

[8] K. Darby, "An examination of the full electrostatic precipitation process for cleaning of gases," in Proceedings 10th Particulate Control Symposium and 5th ICESP Conference on ESPs, pp. 117, Washington, DC, USA, 1993, EPRI TR-103048 V2.

[9] FLSmidth Airtech, Electrostatic Precipitator, Air Pollution Control, 2010.

[10] A. Strehlow and M. Schmoch, "Comparison of techniques for electrode rapping in electrostatic precipitators," Proceedings of the International Conference on Electrostatic Precipitation (ICESP '01), Birmingham, Ala, USA, May 2001.

[11] L. Lillieblad, M. Thimanson, K. Porle, and H. Jacobson, "On dust cake removal in electrostatic precipitators," Proceedings of the International Conference on Electrostatic Precipitation (ICESP '00), May 2000.

[12] S. S. Manson and G. R. Halford, Fatigue and Durability of Structural Materials, ASM International, 2006.

[13] R. Brooks, "Fatigue fracture of stainless steel wires in an electrostatic precipitator at a paper plant," in Handbook of Case Histories in Failure Analysis, vol. 1, ASM International, 1992.

[14] L. Witek, "Numerical stress and crack initiation analysis of the compressor blades after foreign object damage subjected to high-cycle fatigue," Engineering Failure Analysis, vol. 18, no. 8, pp. 2111-2125, 2011.

[15] F. Bagnoli, L. Allegrucci, M. Colavita, and M. Bernabei, "Fatigue failure of a stainless steel wires used in a hydraulic pressure line," Engineering Failure Analysis, vol. 16, no. 5, pp. 1404-1411, 2009.

[16] L. Witek, M. Wierzbińska, and A. Poznańska, "Fracture analysis of compressor blade of a helicopter engine," Engineering Failure Analysis, vol. 16, no. 5, pp. 1616-1622, 2009.

[17] V. Infante, J. M. Silva, M. de Freitas, and L. Reis, "Failures analysis of compressor blades of aeroengines due to service," Engineering Failure Analysis, vol. 16, no. 4, pp. 1118-1125, 2009.

[18] ABAQUS 6.10-1 Software Dassault Systèmes Simulia Corporation, Providence, RI, USA, 2010.

[19] A. P. Nowak, "Measurement verification of the hybrid finite element method," in Proceedings of the 4th European Conference on Computational Mechanics (ECCM '10), Paris, France, May 2010.

[20] A. Nowak and S. Wojciech, "Optimisation and experimental verification of a dust-removal beater for the electrodes of electrostatic precipitators," Computers and Structures, vol. 82, no. 22, pp. 1785-1792, 2004. 

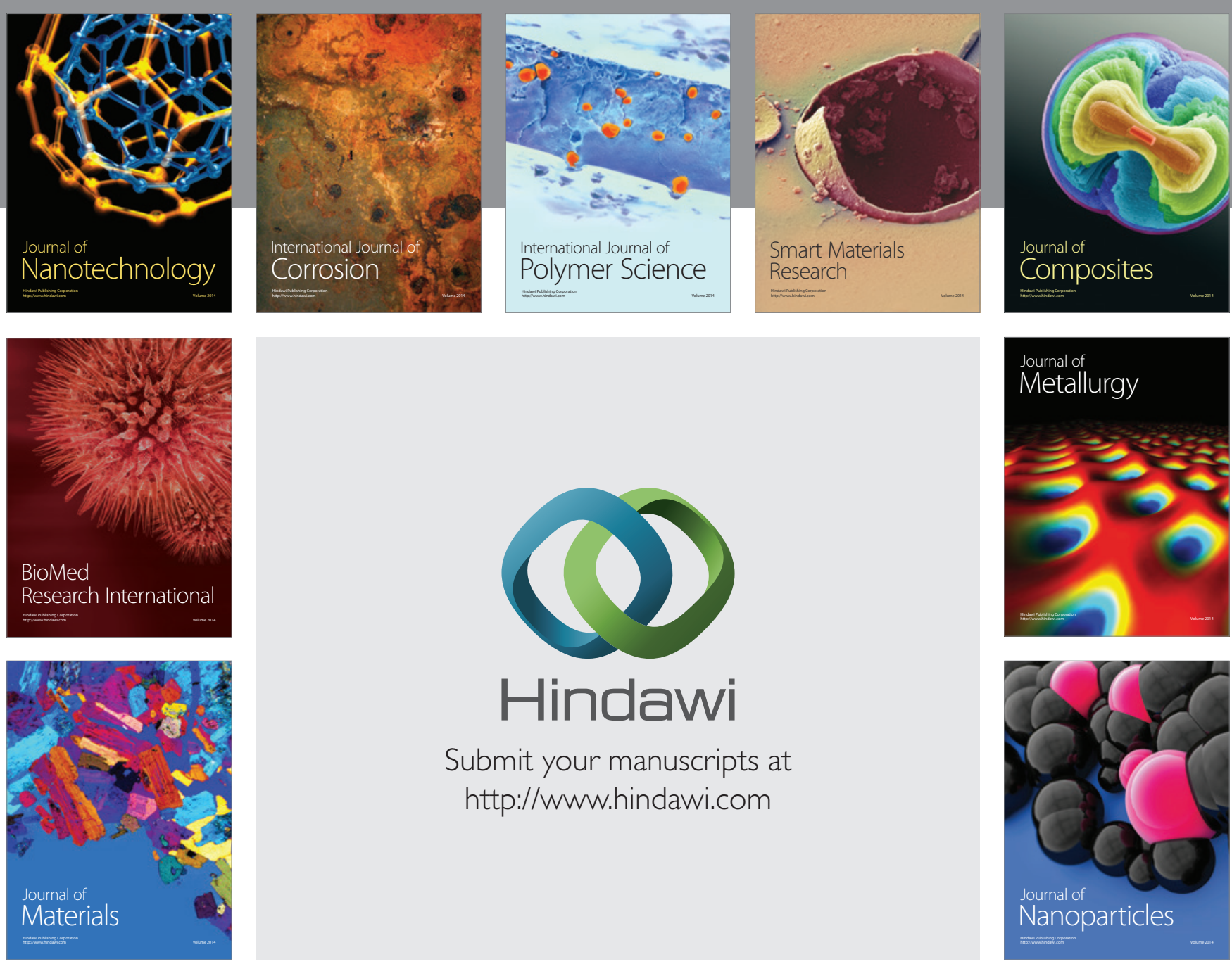

Submit your manuscripts at http://www.hindawi.com
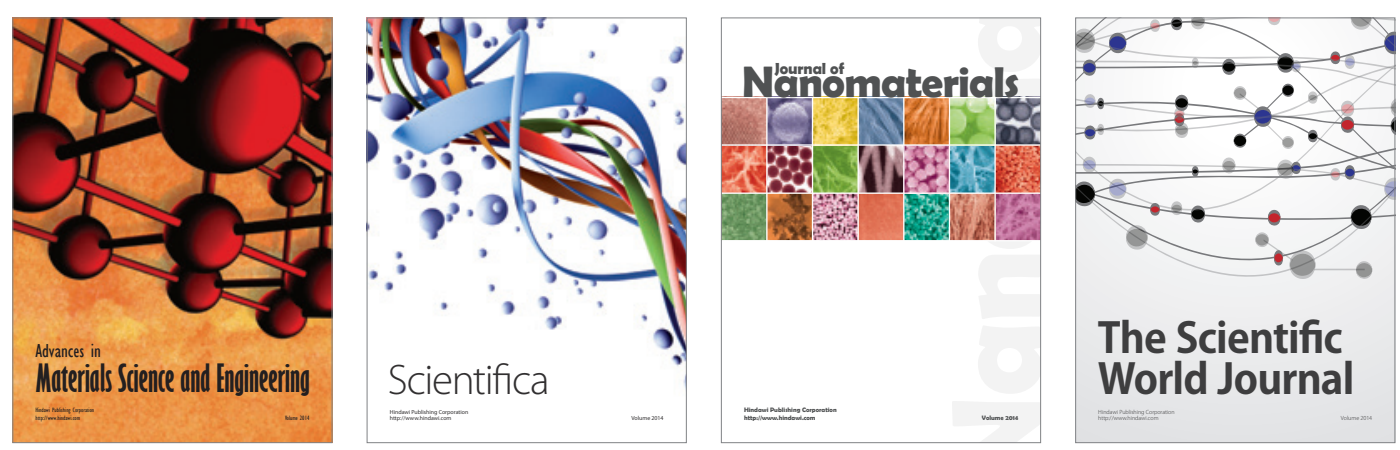

\section{The Scientific World Journal}
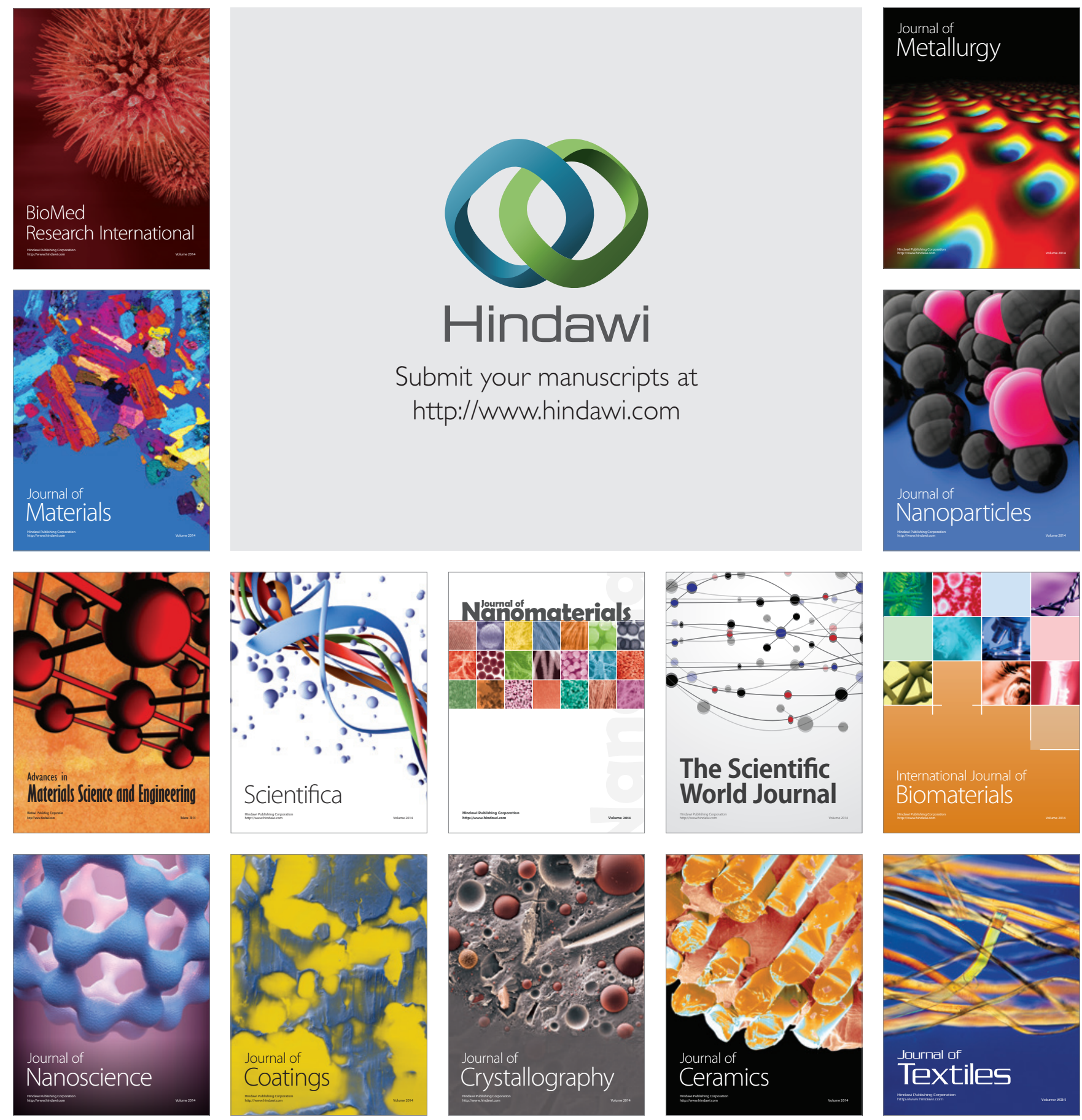